\title{
Validity and reliability of the Turkish version of "cardiac rehabilitation barriers scale"
}

\author{
Özge Keniş Coşkun ${ }^{1}$, İlker Yağcı ${ }^{1}$, Selma Göçmen ${ }^{1}$, Beste Özben Sağdıç ${ }^{2}$ \\ (1) Marmara University, Faculty of Medicine, Department Physical Therapy and Rehabilitation, Istanbul, Turkey \\ (2) Marmara University, Department of Cardiology, Istanbul, Turkey
}

Date submitted:

Nov 19, 2018

Date accepted:

Jan 07, 2019

Online publication date:

June 15, 2019

\section{Corresponding Author: \\ Özge Keniş Coşkun \\ Marmara University, Faculty of \\ Medicine, Department Physical \\ Therapy and Rehabilitation, \\ Istanbul, Turkey \\ ozgekenis@gmail.com}

Keywords: Barriers, cardiac

rehabilitation, reliability, validity.

\begin{abstract}
Aims:Cardiac rehabilitation (CR) has shown to be an effective treatment, but the patient participation and referral rates are low both globally and in Turkey. This study aims to translate and show the consistency and validity of 'Cardiac Rehabilitation Barriers Scale' in Turkish.

Methods:Cardiac Rehabilitation Barriers Scale has been translated into Turkish as Kardiyak Rehabilitasyonda Engeller Skalası'(KRES). The translated version has been applied to 59 patients who have been referred to the Cardiopulmonary Rehabilitation unit after acute myocardial infarction but could not attend the sessions or missed their sessions.

Results:In the statistical analyses, The Kaiser-Meyer-Olkin value was 0.668 and Barlett's test was significant $(p<0.001)$. In factor analysis, 5 factors were identified: The first factor reflects extrinsic limitations on the patients' access. The second factor reflects problems about patients' information about CR. The third factor is logistical problems. The fourth factor reflects the perceived need for CR. The fifth factor consists of only one item 'other health problems prevent me from going.' Internal consistency of all subscales revealed satisfactory internal consistency (Cronbach's alpha $\geq 0.7$ ).

Conclusions:KRES is a valid and consistent tool in evaluating barriers in CR in Turkish patients.
\end{abstract}

\section{Introduction}

Cardiovascular diseases are one of the major causes of mortality in Turkey. They cause an enormous burden on emergency services and the health care system, which makes them a public health problem. Moreover, there is a significant number of patients who have cardiovascular risks such as high blood cholesterol levels, lack of activity and exercise, impaired glucose control and the presence of diabetes mellitus, and these risk factors are not dealt with as they should (1). Cardiac rehabilitation (CR), as a multidisciplinary program individually tailored to the needs of patients with cardiovascular diseases, focuses on reducing these cardiovascular risk factors such as inactivity and elevated blood cholesterol levels. CR involves a structured and supervised outpatient aerobic exercise program performed with treadmills or stationary bikes that are appropriately equipped to monitor the patients' blood pressure, cardiac rhythm and oxygen saturation during the exercise session. It also includes sessions to inform the patient about the disease itself and ways to cope with the disease process, trying to minimize the negative impacts of the disease on the patients' daily life. It usually consists of three sessions per week for a period of ten to twelve weeks, while it can be applied differently in different centers. Current practice guidelines support the use of CR programs in patients after acute coronary syndrome, coronary artery bypass grafting, coronary stent placement, valve surgery, and stable chronic systolic heart failure (2). It has been documented to be safe and effective in decreasing mortality and increasing quality of life in patients with a history of cardiovascular disease (3). Even with the current evidence, patients are not referred to $\mathrm{CR}$ programs with low enrollment rates, do not have information about the presence and the content of these programs or have difficulties in adhering to the programs themselves after their referral with high-dropout rates. This dissonance is multifactorial and is influenced by patients, doctors and healthcare systems all around the globe (4). Cardiac Rehabilitation Barriers Scale is a multi-level measure of these barriers that has been developed and validated orginally in English in 2012. It is a 21-item scale that assesses patients' perceptions of patient, provider and health system-level barriers to cardiac rehabilitation utilization. It can be applied both at enrollment and during participation and it is applicable to all cardiac patients (5). 
This scale has also been translated and validated in Portuguese and Korean $(6,7)$. The aim of this study is to translate and validate this scale in Turkish.

\section{Methods}

The study has been done in Physical Medicine and Rehabilitation and Cardiology Departments between January 2018 and June 2018. The ethical approval number is $18 / 263$. The study has been approved by the local ethical committee. Patients between the ages of 18-65, whose mother tongue was Turkish, who can read and write and who had been referred to CR after an acute coronary syndrome but could not attend or missed their sessions due to various reasons were included in the study. Patients who had been regularly attending their $C R$ sessions and patients who have been referred to CR for other pathologies than acute coronary syndrome (i.e., pulmonary hypertension) were excluded. All patients have given written informed consent. Patients demographic properties like age, sex, education, body mass index (BMI) history of diabetes mellitus, hypertension, hyperlipidemia, and current cigarette smoking status were recorded. Cardiac Rehabilitation Barriers Scale (CRBS) scale consists of 21 questions, and patients answer them on a 5-point Likert scale. 1 point means definitely disagree while 5 points mean definitely agree. The original English version defined four subscales: perceived need/ health factors ( 9 questions), logistic factors (5 questions) work conditions/ time constraints (3 questions) and comorbidities - functional status (4 questions). Higher scores indicate higher barriers in CR.

Necessary permissions have been obtained from the original creator of the scale before commencing with the study. This scale has been translated first by a translator whose mother tongue is Turkish and is advanced in English. This translation was then translated back to English by another independent translator. This second English version has been translated into Turkish, and the two Turkish versions were compared. The inconsistencies and problems in the meaning of the questions were overviewed, potential misunderstandings were addressed, and a final version was established by the study team (8). This final version is named 'Kardiyak Rehabilitasyonda Engeller Skalası' (KRES). The patients were also asked about their opinions on the construction, usefulness, and scope of the scale and their answers were evaluated via a $100 \mathrm{~mm}$ visual analog scale (7).

\section{Statistical analyses}

Patient characteristics were assessed by basic descriptive tests. Construct validity, factor structure and internal consistency of identified factors were analyzed. The suitability of factor analysis was determined by the Kaiser-Meyer-Olkin (KMO) measure of sampling adequacy, and Bartlett's sphericity test. The construct validity was evaluated by principle components analysis, and the factor structure rotated using orthogonal rotations (varimax). Factors with eigenvalues greater than 1.0 were extracted (9). After the factors were extracted, a correlation matrix was generated using varimax rotation with Kaiser normalization. Factor loadings greater than 0.40 on only one factor were taken into consideration (10). If an item loaded on multiple factors, then the factor with the highest loading was considered for interpretation. The internal consistency of the subscales was tested with Cronbach's alpha and values $\geq 0.7$ were deemed to be satisfactory. The level of significance was set as $p<0.05$. SPSS version 22 (IBM, Armonk, NY, USA) was used for analysis.

\section{Results}

A total of 59 patients were included. Patient characteristics are summarized in Table 1. The $\mathrm{KMO}$ value was 0.668 and Barlett's test was significant $(p<0.001)$, which indicate that our sample size of 59 patients was ample for proceeding with factor analyses. Eigenvalue and percent of variance explained by each factor are summarized in Table 2 . Five factors were extracted from the analyses. The first factor reflects extrinsic limitations on the patients' access. The second factor reflects problems about patients' information about CR. The third factor is logistical problems. The fourth factor reflects the perceived need for CR. The fifth factor consists of only one item 'other health problems prevent me from going.' Internal consistency of all subscales revealed satisfactory internal consistency (Cronbach's alpha $\geq 0.7$ ) aside from factor five that consists of only one question. Patients' opinions on the effectiveness and construction of the scale have been summarized in Table 3 .

\begin{tabular}{|c|c|}
\hline Age mean $\pm S D(\min -\max )$ & $55.03 \pm 12.77(21-80)$ \\
\hline Male $n,(\%)$ & $39,(66.1)$ \\
\hline Education >primary school n, (\%) & $30,(50.9)$ \\
\hline Retired $n,(\%)$ & $21,(35.5)$ \\
\hline $\mathrm{BMI}$ mean $\pm \mathrm{SD}(\min -\max )$ & $28.51 \pm 4.04(19.53-42.50)$ \\
\hline LVEF mean \pm SD $(\min -\max )$ & $50.89 \pm 12.13(20-68)$ \\
\hline History of DM n, (\%) & $14(23.7)$ \\
\hline History of HT n, (\%) & $43(72.9)$ \\
\hline History of HL n, (\%) & $34(57.6)$ \\
\hline Current Smoker $\mathrm{n},(\%)$ & $18(30)$ \\
\hline
\end{tabular}

\section{Discussion}

This study aimed to translate and adapt the CRBS to Turkish and show the consistency and validity of the translated version. All 21 questions were included in the final translated version. Psychometric assessments have demonstrated that KRES is a consistent and valid scale and can be used to define barriers of cardiac rehabilitation in Turkish patients who have undergone acute coronary syndrome.

In accordance with the previous validation studies, this study has identified five factors within the newly translated scale. These factors are extrinsic limitations, patient's lack of information, logistics, perceived need and the presence of health problems. The identified factors are quite similar both to the previous validations and the original version, which show that the original questions on this scale can be useful in detecting the barriers of CR in Turkey. In the clinical setting, most common barriers that practitioners deal with are the lack of referrals, hence the lack of information of the patient about $C R$, and logistical problems. But there are no data available to show why these patients do not attend to CR programs, and these remain as clinical, daily-life observations. A recent review indicated that lack of human and financial resources as well as space constraints were reported as the significant barriers to delivery of CR all around the globe (11). In Iran, it has been documented that only $8.3 \%$ of the patients who have undergone coronary artery bypass surgery are referred to CR. It has been shown in the same study group that providing appropriate awareness 
Table 2: Maximum likelihood factor analyses, percentage of variance and Eigenvalues for factors

\begin{tabular}{|c|c|c|c|c|c|}
\hline & Factor 1 & Factor 2 & Factor 3 & Factor 4 & Factor 5 \\
\hline \multicolumn{6}{|l|}{ CRBS item } \\
\hline . . of work responsibilities & 0.819 & & & & \\
\hline . . travel & 0.817 & & & & \\
\hline . . severe weather & 0.788 & & & & \\
\hline . . I already exercise at home or in my community & 0.769 & & & & \\
\hline . . .of family responsibilities & 0.713 & & & & \\
\hline ... of time constraints & 0.446 & & & & \\
\hline$\ldots$. I think I was referred but the rehab program didn't contact me & & 0.743 & & & \\
\hline ... I prefer to take care of my health alone & & 0.739 & & & \\
\hline ... it took too long to get referred and into the program & & 0.715 & & & \\
\hline ...I am too old & & 0.659 & & & \\
\hline ...I didn't know about CR & & 0.537 & & & \\
\hline . my doctor didn't feel it was necessary & & 0.456 & & & \\
\hline . of distance & & & 0.900 & & \\
\hline . . of transportation problems & & & 0.886 & & \\
\hline .of cost & & & 0.782 & & \\
\hline . . I find exercise tiring or painful & & & & 0.838 & \\
\hline ...I don't have the energy & & & & 0.732 & \\
\hline . . II don't need CR & & & & 0.614 & \\
\hline $\begin{array}{l}\text {...many people with heart problems don't go to CR and they are } \\
\text { fine }\end{array}$ & & & & 0.596 & \\
\hline ...I can manage on my own & & & & 0.435 & \\
\hline ... other health problems prevent me from going & & & & & 0.854 \\
\hline \multicolumn{6}{|l|}{ Extraction sums of squared loadings } \\
\hline Eigenvalue & 5.182 & 3.262 & 2.013 & 1.550 & 1.138 \\
\hline Varience explained\% & 24.675 & 15.534 & 9.588 & 7.379 & 5.419 \\
\hline \multicolumn{6}{|l|}{ Rotation sums of squared loadings } \\
\hline Eigenvalue & 3.036 & 2.993 & 2.828 & 2.423 & 1.500 \\
\hline Varience explained $\%$ & 14.457 & 14.251 & 13.469 & 11.540 & 7.143 \\
\hline Reliability (Crohnbach's alpha) & 0.743 & 0.777 & 0.888 & 0.720 & - \\
\hline
\end{tabular}

\section{Table 3: Subjects' opinions about the questionnaire}

VAS scores Mean \pm Standard Deviation

Is this questionnaire useful to assess barriers of cardiac rehabilitation

$79.5 \pm 24.2$

Do you think that this questionnaire assess your barriers of cardiac rehabilitation?

$81.4 \pm 20.8$

Is the length of the questionnaire appropriate?

$76.4 \pm 28.4$

Are the questions clearly understandable?

$76.9 \pm 27.5$

Is this questionnaire well-organized?

$77.6 \pm 27.6$

What is your opinion about the readability of the questionnaire?

$77.5 \pm 28.6$

Is it easy to fill-in this questionnaire?

$74.2 \pm 27.3$

What do you think about the layout of the questionnaire?

$75.6 \pm 28.4$

VAS: visual analog score 
about the benefits of $\mathrm{CR}$ for patients with regard to their job status, coronary history, and perception about the illness risk factors can be useful in referral to CR (12). As Iran has similar demographics and culture to Turkey, these findings can also have a repercussion here. But another review has documented that the cost of CR to the patients and the lack of public funding is one of the main reasons why attendance rates are low around the world (13). It is certain that this is not the case in Turkey. Here, a program including 30 sessions per year is covered by health insurance for all cardiovascular patients. Therefore, not all global data can be applied, and it is crucial to define the current state of CR in Turkey. Without assessing the existing barriers of CR, it would not be possible to increase the patients' attendance rates and their involvement in CR programs. A recent Cochrane review has stated that interventions targeting patient-identified barriers may be successful in improving attendance and may help to utilize CR programs more efficiently (14).

Although the referral rates are still low, cardiac rehabilitation has been gaining more attention in the care of patients with cardiovascular diseases in Turkey. The numbers of existing centers that specialize on this subject have increased but still not sufficient to accommodate every potential patient even if they were all referred. The costliness of founding an establishment for this purpose and the inadequate referral rates are among the reasons why the number of these centers are not increasing as rapidly as they should. Also, the potential locations of these centers are now being moved away from the city centers with the construction of newer, bigger and better-equipped hospitals in the suburban areas of major cities. This may contribute to the existing barriers, such as distance and difficulties in logistics. Other factors are more universal, like low referral rates despite the proven effectiveness and the lack of adherence of the patients. Low referral rates may also be due to the overwhelming burden on the cardiologists due to the constant overcrowding of emergency departments, outpatient and inpatient clinics in Turkey. These aspects of the health system and referral systems can be evaluated in the future, but it is beyond the aim of this scale. However, it must be stated that to improve the current state of our health system and to decrease overcrowding issues within the hospitals, and more emphasis must be given to preventive approaches such as CR. The lack of adherence is definitely influenced by logistic difficulties, namely the state and presence of public transport and how it can be challenging to utilize public transportation on a regular basis for a patient with cardiovascular problems. Moreover, it must also be kept in mind that patients in Turkey are not as active as they should be, with exercise habits differing significantly from patients in elsewhere in the world, and the level of activity is heavily influenced by socioeconomic factors $(15,16)$. It has been shown that in the results of the Danish registry, patients older than 70 years, retired, low educated and with a lower annual income are less willing to participate in CR programs (17). KRES will help Turkish professionals, both doctors, and government officials that are interested in this subject, to define the reasons why patients are not attending to CR programs and will help to improve the quality of these services around the country.

One of the weaknesses of this study is that the test-retest reliability for the translated version was not assessed. However, it was within acceptable limits in previous validation studies with intra-class correlation coefficients of 0.64 (5) and 0.68 (6) and therefore was not assessed in this study.

\section{Conclusion}

KRES is a valid and consistent tool in evaluating barriers in $\mathrm{CR}$ in Turkish patients. It can be used in further research to detail the needs and problems in CR.

\section{Acknowledgments}

OKC has participated in design, literature search and statistical analyses. SG has participated in patient recruitment and obtaining data. IY and BOS have both participated in the design and supervising in the writing and editing process.

\section{Conflict of interests}

Authors declare no conflicts of interests.

\section{References}

1. Onat A, Karakoyun S, Akbas T, et al. [Turkish Adult Risk Factor survey 2014: Overall mortality and coronary disease incidence in Turkey's geographic regions]. Turk Kardiyoloji Dernegi arsivi: Turk Kardiyoloji Derneginin yayin organidir. 2015;43(4):326-332.

2. McMahon SR, Ades PA, Thompson PD. The role of cardiac rehabilitation in patients with heart disease. Trends in cardiovascular medicine. 2017;27(6):420-425.

3. Anderson L, Thompson DR, Oldridge N, et al. Exercise-based cardiac rehabilitation for coronary heart disease. The Cochrane database of systematic reviews. 2016(1):Cd001800.

4. Grace SL, Krepostman S, Brooks D, et al. Referral to and discharge from cardiac rehabilitation: key informant views on continuity of care. Journal of evaluation in clinical practice. 2006;12(2):155-163.

5. Shanmugasegaram S, Gagliese L, Oh P, et al. Psychometric validation of the cardiac rehabilitation barriers scale. Clinical rehabilitation. 2012;26(2):152-164.

6. Ghisi GL, Santos RZ, Schveitzer V, et al. Development and validation of the Brazilian Portuguese version of the Cardiac Rehabilitation Barriers Scale. Arquivos brasileiros de cardiologia. 2012;98(4):344-351.

7. Baek S, Park HW, Lee Y, Grace SL, Kim WS. Translation, Cross-cultural Adaptation and Psychometric Validation of the Korean-Language Cardiac Rehabilitation Barriers Scale (CRBS-K). Annals of rehabilitation medicine. 2017;41(5):858-867.

8. Wild D, Grove A, Martin M et al. Principles of Good Practice for the Translation and Cultural Adaptation Process for Patient-Reported Outcomes (PRO) Measures: report of the ISPOR Task Force for Translation and Cultural Adaptation. Value in health: the journal of the International Society for Pharmacoeconomics and Outcomes Research. 2005;8(2):94-104.

9. Kaiser HF. The application of electronic computers to factor analysis. Educational and psychological measurement. 1960;20(1):141-151.

10. Field A. Discovering statistics using IBM SPSS statistics: sage; 2013.

11. Pesah E, Supervia M, Turk-Adawi K, Grace SL. A Review of Cardiac Rehabilitation Delivery Around the World. Progress in cardiovascular diseases. 2017;60(2):267- 
280.

12. Soroush A, Heydarpour B, Komasi S, Saeidi M, Ezzati P. Barriers for the referral to outpatient cardiac rehabilitation: A predictive model including actual and perceived risk factors and perceived control. Annals of cardiac anaesthesia. 2018;21(3):249-254.

13. Moghei M, Pesah E, Turk-Adawi K, et al. Funding sources and costs to deliver cardiac rehabilitation around the globe: Drivers and barriers. International journal of cardiology. 2018 S0167-5273(18)34389-34384.

14. Karmali KN, Davies P, Taylor F, Beswick A, Martin N, Ebrahim S. Promoting patient uptake and adherence in cardiac rehabilitation. The Cochrane database of systematic reviews. 2014(6):Cd007131.

15. Yildirim G, Ince ML, Muftuler M. Physical activity and perceptions of neighborhood walkability among Turkish women in low and high socio-economic environments: an exploratory study. Perceptual and motor skills. 2012;115(2):661-675.

16. Erem C, Hacihasanoglu A, Kocak M, Deger O, Topbas M. Prevalence of prehypertension and hypertension and associated risk factors among Turkish adults: Trabzon Hypertension Study. Journal of public health (Oxford, England). 2009;31(1):47-58.

17. Graversen CB, Eichhorst R, Ravn L, Christiansen SSR, Johansen MB, Larsen ML. Social inequality and barriers to cardiac rehabilitation in the rehab-North register. Scandinavian cardiovascular journal: SCJ. 2017;51(6):316322. 